Article

\title{
The Impacts of Different Green Manure on Soil Microbial Communities and Crop Health
}

\author{
Hongwu Yang ${ }^{1}$, Jiaojiao Niu ${ }^{2,3}$, Jiemeng Tao ${ }^{2,3}$, Yabing Gu ${ }^{2,3}$, Chao Zhang ${ }^{1}$, \\ Siyuan She ${ }^{2,3}$, Wu Chen ${ }^{1}$, Hongqi Yang ${ }^{1}$ and Huaqun Yin ${ }^{2,3, *}$ \\ 1 College of agronomy, Hunan Agricultural University, Changsha 410128, China; \\ hongwuyang@foxmail.com (H.Y.); qinchong@csu.edu.cn (C.Z.); csyhq2009@163.com (H.Y.) \\ 2 School of Minerals Processing and Bioengineering, Central South University, \\ Changsha 410083, China; 135611006@csu.edu.cn (J.N.); taojiemeng@csu.edu.cn (J.T.); \\ guyabing0207@163.com (Y.G.); siyuandaily@126.com (S.S.) \\ 3 Key laboratory of Biometallurgy, Ministry of Education, Changsha 410083, China \\ * Correspondence: yinhuaqun_cs@sina.com; Tel: 86(731)88830546
}

\begin{abstract}
Green manure could improve soil nutrients and crop production, playing a significant role in sustainable agriculture. However, the impacts of green manure on crop health and the roles soil microbial communities play in the process haven't been clarified clearly yet. In this study, we investigated soil microbial community composition and structure in four tobacco farmlands, which were treated with different green manure (control, ryegrass, pea and rape), using 16S rRNA gene amplicons sequencing. Results showed that green manure had significant impacts on soil properties, microbial communities and tobacco health. First, soil total C, N and Ca content increased significantly in groups treated with green manure than control. Second, soil community diversity was significantly higher in groups treated with green manure. Third, green manure especially ryegrass, decreased tobacco disease (bacterial wilt) rate dramatically, and the process might be mediated by soil microbial communities. On the one hand, several microbial populations were found to be potentially disease inducible or suppressive. For example, the abundances of Dokdonella and Rhodanobacter were positively correlated to tobacco disease rate, while Acidobacteira_Gp4 and Gp6 had negative correlations with tobacco disease. On the other hand, soil microbial communities were shaped by soil properties (e.g., $\mathrm{pH}, \mathrm{C}$ and $\mathrm{N}$ content). In conclusion, our research showed that green manure could increase soil nutrients directly, and further improve tobacco health mediated by soil microorganisms, which may shed light on revealing interactions among soil properties, microorganisms and plants.
\end{abstract}

Keywords: green manure; soil microbial communities; crop health; Illumina sequencing

\section{Introduction}

Continuous cropping and inadequate replacement of nutrients removed in harvested materials or lost through erosion, leaching or gaseous emissions deplete fertility and cause soil organic matter levels to decline [1]. Thus, a large part of the increased yields of global cereal production resulted from great inputs of fertilizer. However, chemical fertilizer, industrially produced $\mathrm{NH}_{4}$ and $\mathrm{NO}_{3}$, had negative impacts on environments and ecosystem, like the eutrophication of aquatic habitats, and increasing emission of gases that have critical roles in air pollution [2]. Meanwhile the 
loss of nutrients necessitate the expense of increased fertilization [3]. In a word, traditional agricultural practices have negative impacts on environments and reduce the ability of ecosystems.

Green manure is a crop used primarily as a soil amendment and a nutrient source for subsequent crops, having grate potential in increasing soil organic matter, pest control and increasing crop productivity [4]. It could increase soil organic matter, especially available nitrogen, and improve crop productivity (e.g., rice and wheat), and it was also reported that the concentrations of $\mathrm{Ca}, \mathrm{K}, \mathrm{Mg}$, and $\mathrm{Mn}$ were higher in soils amended with green manure than synthetic fertility amendments [5, 6]. More importantly, soils in organic production systems lost less nitrogen into nearby water systems than did conventional production systems [7]. As for the influences of fertilizer on soil microbial organisms, it was reported that the amount of soil nitrogen in fields under conventional production systems has been negatively correlated with soil microbial components, whereas soil nitrogen in fields under organic production was positively correlated with soil microbial components [8]. For example, red clover manure increased and maintained higher bacterial and fungal biomass and high rates of enzyme (arylsulphatase) activity compared to control treated with chemical fertilizer [9]. Collectively, green manure or organic fertilizer was equally as well in improving soil nutrients and crop production as chemical fertilizer [10], but more environmentally friendly, playing a significant role in sustainable agriculture.

The impacts of green manure on crop disease are still controversial, probably due to that different manure had different impacts on soil microbial communities [11]. Soil-borne pathogens can be either actively suppressed by organic amendments or enhanced, depending on soil health conditions. A research demonstrated that green manure had no suppressive effect on Pythium (pathogenic to lettuce) population, and inferred that a strong increase in microbial activity may reduce $\mathrm{N}$ availability of crops [12]. The negative effects of green manure on crop health were verified in a study, that soil amendment with red clover green manure and compost increased the incidence of disease in wild mustard seedlings and dissolved organic carbon concentration was weakly correlated with disease rate [13]. However, there were also studies suggested that green manure treatments may achieve disease control by activating pathogen inhibitors (e.g., streptomycete), or by releasing allelochemicals generated during product storage or by subsequent microbial decomposition [14-16]. All in all, the issue needs to be explored further.

The complex relationship between soil microbial communities and plants, and the technical limitation in revealing composition and structure of microbial communities also hinder revealing relationship between green manure and crop health. The soil microbial community composition and structure are so sophisticated that many bacteria, which may affect tobacco health, still remain uncultured or unknown [17]. The development of metagenomic sequencing provides us an opportunity to explore the less abundant and primarily uncultured microbial communities. Although pyrosequencing analysis of 16S rRNA genes have been used to investigate the soil microbial communities, but few studies concern the impacts of green manure [18]. Studies in this area used isolates of soil-borne fungal pathogens or disease inhibitors to perform in vitro pathogen inhibition assays, ignoring potential disease inducible or suppressive microbial populations $[14,15]$. In this study, Illumina MiSeq sequencing of 16S rRNA genes was used, which has been demonstrated to be an effective technology in capturing the less abundant taxa [19]. We investigated the impacts of different green manure on soil properties, microbial communities and tobacco health, 
in order to (i) find the most effective green manure in controlling tobacco disease; (ii) clarify the impacts of green manure on soil properties and microbial communities; (iii) explore the relationship among green manure, soil microbial populations and tobacco health.

\section{Materials and Methods}

\section{Site description and sampling}

As a large scale investigational study, four farmlands with similar soil type were selected. They were located in Xiangxi, Hunan province. Tobacco had been cultivated under different green manures, which were control (no manure), ryegrass, pea, and rape. Ten samples were collected from each field using checkerboard sampling method on July $28^{\text {th }}$ (tobacco mature stage) with the permission of the owners. A hole puncher ( $3 \mathrm{~cm}$ in diameter, $20 \mathrm{~cm}$ in depth) was used to collect soils between tobacco plants. Each soil sample was about $400 \mathrm{~g}$. The number of tobacco plants with bacterial wilt was counted to calculate tobacco disease rate of a farmland according to the disease symptom described before [20]. Water content was measured by drying $5 \mathrm{~g}$ of each soil sample in a dry oven for 24 hours at $98^{\circ} \mathrm{C}$. Soil $\mathrm{pH}$ was measured by a $\mathrm{pH}$ measure, and samples were dissolved in sterile water $(5 \mathrm{~g} / 25 \mathrm{~mL})$ before $\mathrm{pH}$ measure. Geochemical properties of soil were analyzed by ICP-AES [21]. Total organic N was quantified by Kjeldahl distillation [22]. The amount of total organic $\mathrm{C}$ was analyzed by potassium dichromate oxidation-ferrous sulphate titrimetry [23].

\section{DNA extration, amplification and sequencing}

After mixing separately, $0.5 \mathrm{~g}$ of each soil sample was used for DNA extraction. DNA was extracted using a MO BIO PowerSoil DNA Isolation Kit (MO BIO, 12888-100) with grinding and SDS lysis followed by gel purification, following the classic protocol at http://ieg.ou.edu/protocol.htm. The V4 region of the 16S rRNA genes were amplified with the primer pair 515F (5'-GTGCCAGCMGCCGCGGTAA-3') and 806R (5'- GGACTACHVGGGTWTCTAAT-3') combined with Illumina adapter sequences, a pad and a linker of two bases, as well as barcodes on the reverse primers [24]. Sample libraries were generated from purified PCR products. The MiSeq 500 cycles kit was used for 2x250 bp paired-ends sequencing on MiSeq machine (Illumina, San Diego, CA).

Sequences with perfect matches to barcodes were split to sample libraries, and were trimmed using Btrim with threshold of QC higher than 20 over five bp window size and the minimum length of $100 \mathrm{bp}$ [25]. Forward and reverse reads with at least $10 \mathrm{bp}$ overlap and lower than 5\% mismatches were joined using Flash [26]. After trimming of ambiguous bases (i.e., N), joined sequences with lengths between 240 and $260 \mathrm{bp}$ were subjected to chimera removal by U-Chime [27]. OTU clustering was through UCLUST at $97 \%$ similarity level [28], and taxonomic assignment was through RDP classifier [29] with a minimal 50\% confidence estimate. The above steps were performed through the Galaxy pipeline (http://zhoulab5.rccc.ou.edu/). Subsequent analyses were performed in R [30]. Singletons were removed for downstream analyses. Samples were rarefied at 18,000 sequences per sample. All the 16S rRNA gene sequences were deposited in GenBank database and the accession number were KR831285 - KR855564. Dissimilarity tests were based on Bray-Curtis dissimilarity index using analysis of similarities (ANOSIM) [31]. Differences in abundances across metal concentration gradient were determined by a one-way analysis of variance (ANOVA) followed by Least Significant Difference (LSD) test 
[32]. Bacterial community diversity was calculated using Shannon-Weiner's diversity $\left(\mathrm{H}^{\prime}\right)$ and evenness. Multivariate statistical analyses of sequencing data were conducted, including detrended correspondence analysis (DCA) for comparing the different functional gene communities. Mantel test [33] and partial least squares path modeling (PLSPM) were used to calculate the correlations between bacterial abundance and environmental attributes. All the analyses were performed in R v. 2.6.1 with the packages vegan and plspm (v. 1.11-3) [30] or online (http://ieg.ou.edu/).

\section{Results}

\section{Characterization of tobacco health and soil properties}

A summary of soil properties, including soil $\mathrm{pH}$, water content and amount of elements (e.g., $\mathrm{Ca}, \mathrm{C}, \mathrm{N}$ ), was described in Table 1. Water content was significantly (p $<0.05$ ) higher in Control. All soil samples were acidic with $\mathrm{pH}$ ranged from 5.10 to 5.76, and higher in Rape and lower in Control and Ryegrass. Soil composition of four groups was also different. For example, the content of $\mathrm{Ca}, \mathrm{C}$ and $\mathrm{N}$ were significantly $(\mathrm{p}<0.05)$ lower in Control than in other groups. Control had the highest tobacco disease rate $(80.45 \%)$, while disease rate was the lowest in ryegrass treated group $(3.38 \%)$ (Table 2).

Table 1. Soil properties in fields treated with different green manures

\begin{tabular}{|c|c|c|c|c|c|c|c|c|}
\hline Sample & $\mathrm{PH}$ & $\begin{array}{c}\text { Water } \\
\text { content }(\%)\end{array}$ & Total N (\%) & Total C (\%) & $\mathrm{Ca}(\mathrm{ppm})$ & $\mathrm{Fe}(\mathrm{ppm})$ & Co (ppm) & $\mathrm{Zn}(\mathrm{ppm})$ \\
\hline Control & $5.10 \pm 0.20$ & $17.07 \pm 1.48$ & $0.096 \pm 0.008$ & $0.852 \pm 0.067$ & $1580.63 \pm 264.78$ & $15277 \pm 1274.81$ & $3.91 \pm 2.37$ & $42 \pm 5.93$ \\
\hline Ryegrass & $5.35 \pm 0.22$ & $14.42 \pm 3.81$ & $0.125 \pm 0.09$ & $1.026 \pm 0.303$ & $2769.60 \pm 481.29$ & $15660 \pm 1858.47$ & $4.89 \pm 2.60$ & $44.80 \pm 7.46$ \\
\hline Pea & $5.45 \pm 0.37$ & $14.25 \pm 0.75$ & $0.12 \pm 0.01$ & $1.106 \pm 0.349$ & $2653.40 \pm 792.17$ & $15475.3 \pm 1885.15$ & $3.84 \pm 2.70$ & $44 \pm 9.44$ \\
\hline Rape & $5.76 \pm 0.53$ & $15.62 \pm 2.18$ & $0.104 \pm 0.003$ & $0.950 \pm 0.084$ & $2473.70 \pm 837.27$ & $15805.5 \pm 3105.41$ & $3.75 \pm 3.38$ & $46.2 \pm 10.30$ \\
\hline ANOVA & $\mathrm{a}, \mathrm{a}, \mathrm{ab}, \mathrm{b}$ & $a, b, b, a b$ & $\mathrm{a}, \mathrm{b}, \mathrm{c}, \mathrm{d}$ & $\mathrm{a}, \mathrm{ab}, \mathrm{b}, \mathrm{ab}$ & $a, b, b, b$ & $\mathrm{a}, \mathrm{a}, \mathrm{a}, \mathrm{a}$ & $\mathrm{a}, \mathrm{a}, \mathrm{a}, \mathrm{a}$ & $\mathrm{a}, \mathrm{a}, \mathrm{a}, \mathrm{a}$ \\
\hline
\end{tabular}

* Significant differences $(p<0.05)$ among four groups are indicated with alphabet.

Table 2. Diversity of microbial communities of four groups and tobacco disease rate

\begin{tabular}{lcccc}
\hline & Control & Ryegrass & Pea & Rape \\
\hline Shannon diversity & $6.637514(\mathrm{a})$ & $6.923182(\mathrm{~b})$ & $6.992128(\mathrm{~b})$ & $6.658385(\mathrm{ab})$ \\
Pielou evenness & $0.833277(\mathrm{a})$ & $0.85387(\mathrm{~b})$ & $0.86093(\mathrm{~b})$ & $0.833226(\mathrm{a})$ \\
Chao value & 10193.43 & 12107.86 & 11800.48 & 12233.25 \\
Disease rate & $80.45 \%$ & $3.38 \%$ & $8.78 \%$ & $22.97 \%$ \\
\hline
\end{tabular}

*Significant $(\mathrm{p}<0.05)$ differences among four groups are labeled with alphabet.

\section{Overview of microbial community diversity}

After resample, we obtained 18000 high-quality 16S rRNA gene sequences per sample. Rarefaction curve showed that the numbers of OTUs were almost saturated in all samples, and enough for community analysis (Figure S1). After clustering at $97 \%$ sequence identity, 14,629 OTUs were identified in this study, out of 127 OTUs were classified as archaea. In domain archaea, $62.28 \%$ of reads were classified as Fervidicoccus, and $26.21 \%$ were unclassified genera of phylum Euryarchaeota. Within the bacterial domain, four major microbial phyla accounted for $55.79 \%$ to $65.39 \%$ of all reads, and they were Proteobacteria $(21.69 \% \sim 41.44 \%)$, Chloroflexi (2.78\% 16.24\%), Acidobacteria (13.05\% 23.62\%), and Actinobacteria (4.13\% 
$8.13 \%$ ). And about $11.78 \%$ to $22.65 \%$ of sequences were not assigned to any known phylum (Figure S2). Shannon diversity index and Pielou evenness index were significantly $(\mathrm{p}<0.05)$ lower in Control $(6.637,0.833)$ and Rape $(6.658,0.833)$, but higher in Ryegrass $(6.923,0.854)$ and Pea $(6.992,0.861)$ (Table 2).

To evaluate the difference of these microbial communities in structure generally, we conducted dissimilarity test and DCA. Dissimilarity test showed that microbial communities were significantly $(p<0.01)$ different among four groups (Table S1). Similar results can also be seen from DCA graph, which showed that samples of each group were well separated, except for that several samples of Rape were clustered with samples of Control (Figure 1).

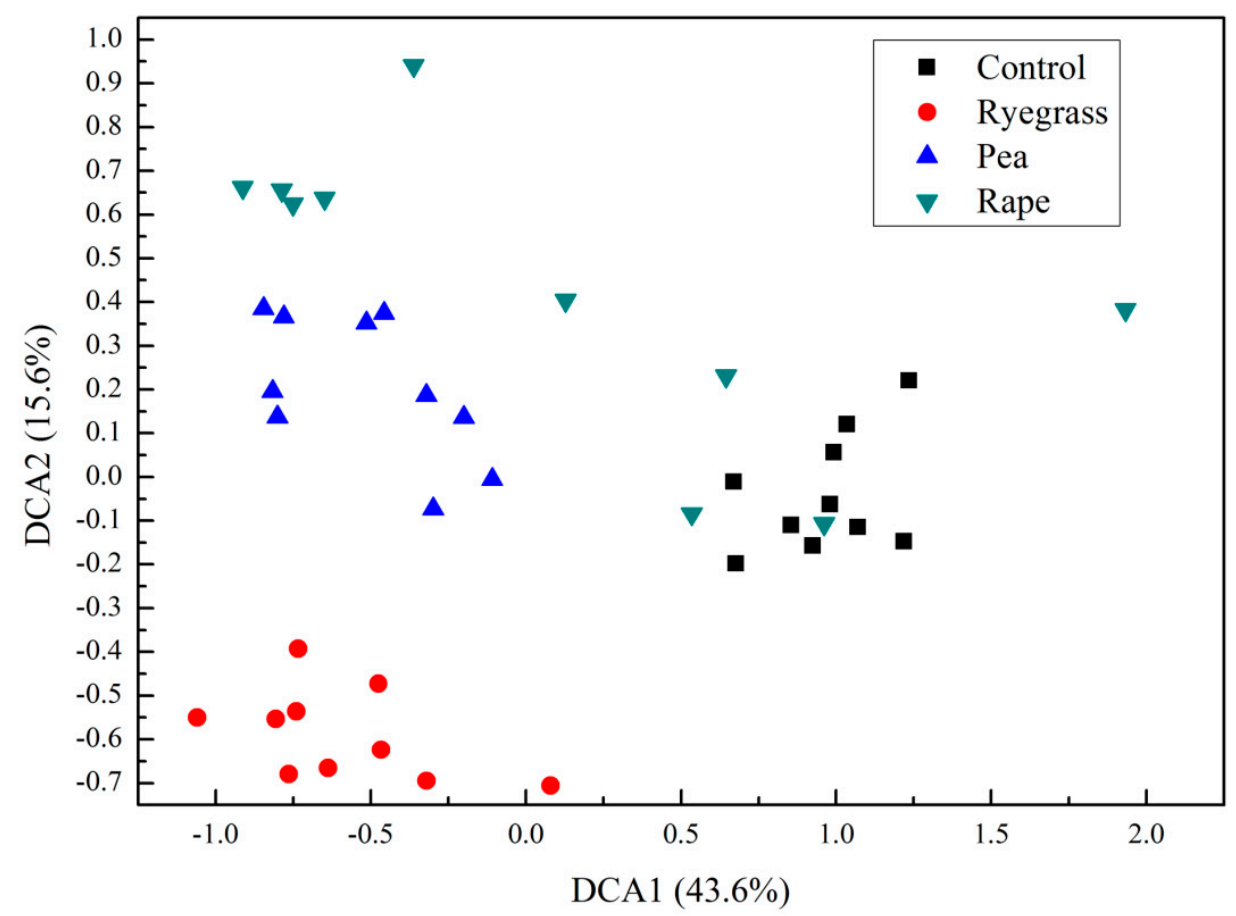

Figure 1. Detrended correspondence analysis (DCA) of 16r RNA gene sequencing data

\section{The impact of different green manure on soil microbial communities}

Fertilization of green manure had significant impacts on soil microbial community composition and structure. At the phylum level, Proteobacteria, Actinobacteria were more abundant in Control; Crenarchaeota was more abundant in Rape; Acidobacteria was more abundant in Pea and had the fewest reads in Control; Chloroflexi and Planctomycetes were more abundant in Ryegrass. At the genus level, Acidobacteria_Gp6, Acidobacteria_Gp4 and Gp16 were more abundant in Pea; Spartobacteriā_genera_incertae_sēis, Gemmatimonas, Dokdonella and Rhodanobacter were more abundant in Control (Figure 2). Among microbial populations that were reported to be related to tobacco health, Ralstonia was significantly more abundant in Control; Pseudomonas was less abundant in Ryegrass; and Bacillus was more abundant in Control and Pea. 


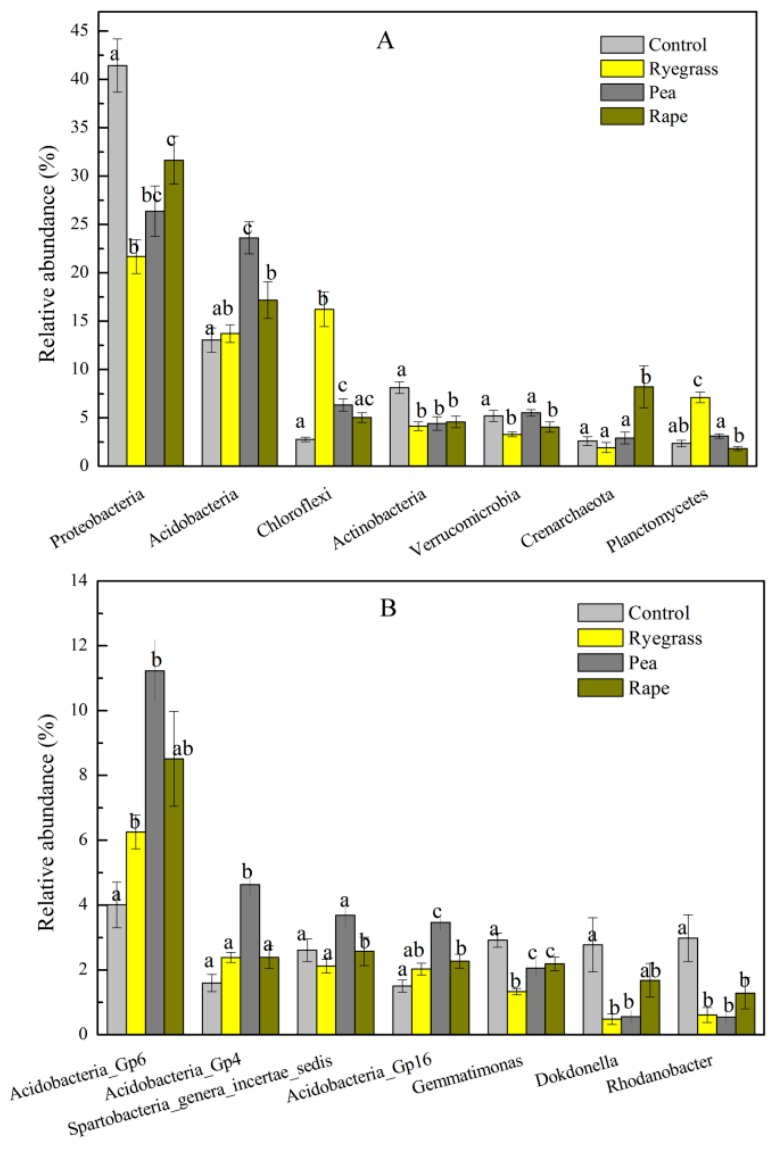

Figure2. Relative abundances of major microbial populations in four groups at the phylum level (a) and the genus level $(b)$. Significant differences $(p<0.05)$ among four groups are labeled with alphabet.

\section{Correlations among soil properties, microbial communities and tobacco health}

Mantel test was conducted to evaluate impacts of soil properties on microbial communities, and results showed that soil water content, $\mathrm{pH}$, and the amount of $\mathrm{Ca}$, $\mathrm{Fe}, \mathrm{C}, \mathrm{N}$ influenced soil microbial communities significantly $(\mathrm{p}<0.05)$ (Table S2). Furthermore, relationship between specific microbial population and environmental factor was analyzed using Pearson correlation. Seven phyla (e.g., Proteobacteria, Actinobacteria) were found to be negatively correlated with soil $\mathrm{Ca}$ content, while Acidobacteria and $B R C 1$ were positively correlated with Ca content. Eight phyla (e.g., Proteobacteria, Actinobacteria) were negatively related to N. And four phyla (e.g., Chloroflexi, Planctomycetes) were positively correlated to N. Seven genera (Acidobacteria_Gp4 Acidobacteria_Gp6) were positively correlated to Ca, ten genera (Dokdonella, Rhodanobacter) negatively. Eight genera were positively correlated to N, 12 genera (Dokdonella, Rhodanobacter) were negatively correlated. Pseudomonas and Bacillus were negatively correlated with N (Table S3).

Both soil properties and microbial populations were related to tobacco disease rate. The abundances of four major (relative abundance $>0.6 \%$ ) phyla (Proteobacteria, Actinobacteria, Gemmatimonadetes and Nitrospira) and eight genera (e.g., Dokdonella, Rhodanobacter) were positively correlated to tobacco disease rate. The abundances of four phyla (Acidobacteria, Chloroflexi, Planctomycetes and WS3) and eight genera (e.g., Acidobacteria_Gp6, Acidobacteria_Gp4) were negatively correlated to tobacco disease rate. Also, soil $\mathrm{Ca}, \mathrm{N}$ and $\mathrm{C}$ contents were negatively 
correlated to tobacco disease rate, while water content, Ammonium N, rapidly available $\mathrm{P}$ and rapidly available $\mathrm{K}$ were positively correlated to tobacco disease rate. Almost all microbial populations that positively correlated with tobacco disease rate were negatively correlated with $\mathrm{N}$ and Ca amount (Table S3). Collectively, PLSPM was constructed to profile the relationship among soil properties, microbial communities and tobacco disease. Results showed that soil properties had impacts on soil microbial communities; both soil properties and microbial communities contributed to tobacco disease (Figure 3). All the correlations were significant ( $\mathrm{p}<$ 0.01 ) in the model. Goodness of fit value was 0.4405 , bigger than 0.35 , indicating that the model was reliable.

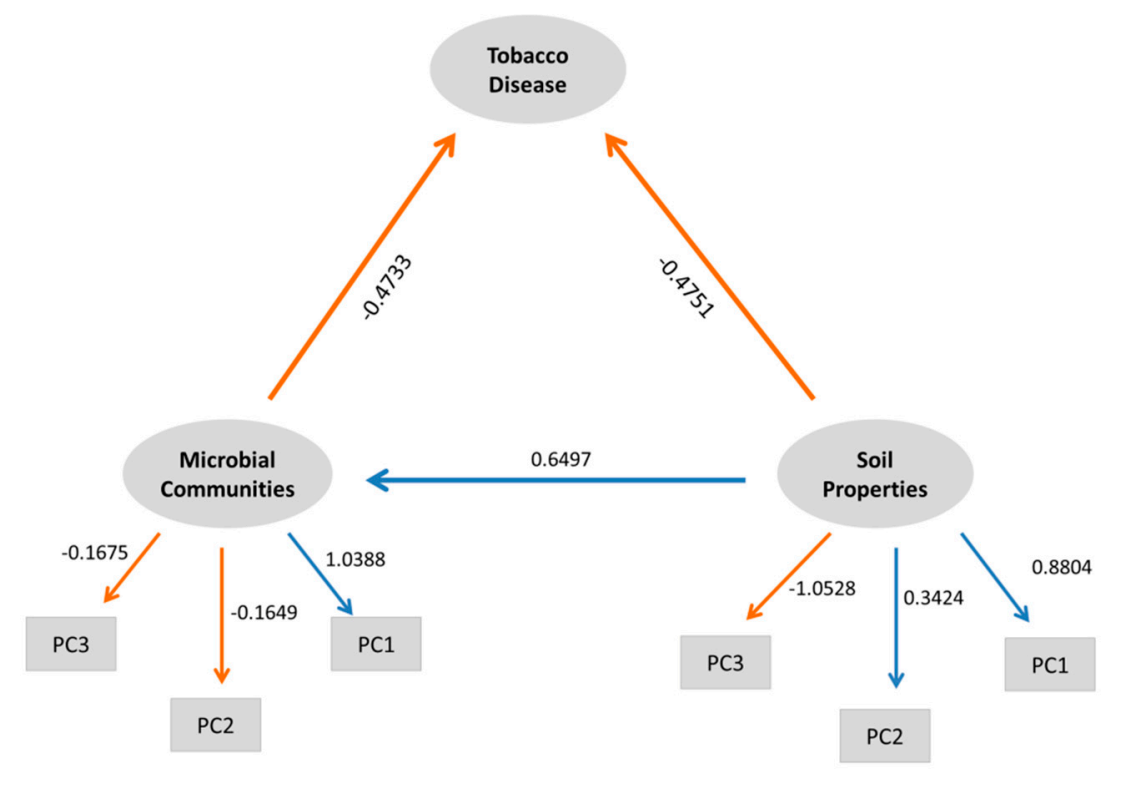

Figure3. Partial least squares path modeling (PLSPM) about correlations among soil properties, microbial communities and tobacco disease

\section{Discussion}

As the potential replacement of chemical fertilizer, green manure could improve soil nutrients and crop production, but its impacts on crop health haven't been clarified clearly yet $[4,11]$. In order to explore the impacts of green manure on tobacco health, and reveal relationship among soil properties, microbial communities and plant disease, 16S rRNA gene sequencing and PLSPM were used in this study. Our analyses showed that all three kinds of green manure could increase soil organic matter, increase soil microbial community diversity and decrease tobacco disease rate compared to the control. And the effects were slightly different among three groups, as ryegrass treated group had the lowest tobacco disease rate. It has been realized that the effect of each green manure on soil properties and crop yield depends upon its chemical composition [34]. Green manure of ryegrass, pea and rape had different composition, thus might influence soil properties in different ways. Tobacco, pea and rape are all dicotyledons, while ryegrass is monocotyledon. Monocotyledon and dicotyledon usually had different nutrient requirements, root exudates and microbial pathogens [35]. For instance, phosphorus mobilized by a dicotyledon (faba bean) 
increases the growth of a kind of monocotyledon (maize) grown in an intercropping system [36]. Similarly, we could speculate that ryegrass manure might affect soil properties and microbial communities differently, resulted from its distinct composition. Not only the most effective green manure in this study, ryegrass was also used as effective green manure for many other crops, such as wheat, maize and potato, due to reducing $\mathrm{N}$ leaching loss over winter and improving $\mathrm{N}$ supply [15, 37], indicating its potential in sustainable agriculture.

First of all, soil properties were affected by green manure, and the changed soil properties were beneficial for tobacco growth. Previous research showed that organic fertilizer greatly increased soil organic $\mathrm{C}$, total $\mathrm{N}, \mathrm{P}$ and $\mathrm{K}$, available $\mathrm{N}, \mathrm{P}$ and $\mathrm{K}$ content [38]. In this study, samples treated with green manures had higher $\mathrm{Ca}, \mathrm{N}$ and $\mathrm{C}$ content. There is no doubt that increased nutrient is beneficial for plant growth and activity of soil microorganisms. But the importance of $\mathrm{Ca}$ hasn't been clarified sufficiently before. $\mathrm{Ca}$ is a necessary element for plant growth, thus may increase tobacco's resistance to pathogen indirectly. Moreover, Moshe Sagi found that the plant homolog can be stimulated directly by $\mathrm{Ca}^{2+}$ to produce $\mathrm{O}_{2}^{-}$, which was considered to be a component of the resistance response of plants to pathogen challenge [39]. Therefore, the increased Ca content by green manure might be key factors in suppressing tobacco disease.

Then, soil microbial communities were influenced by soil properties. It was commenly acknowledged that bacterial and eukaryotic community structures were significantly affected by soil properties, especially $\mathrm{C}$ and $\mathrm{N}$ content [40]. Our results showed that soil microbial community composition and structure were different among four groups, and community diversity was higher in groups treated with green manure. We speculated that the increased biodiversity resulted from the increased soil nutrients. And it has been reported that green manure had positive influence on soil biomass, which was consistent with our result [4]. As for the meaning of the increased biodiversity, there was no direct relationship between biodiversity and function [41], but the decreased biodiversity impair function and productivity of the ecosystem, because the ability of ecosystems to provide some services depends on both the number and type of species in an ecosystem [42, 43]. So soils with the higher biodiversity were more resistant to the stress. In this way, green manure increased biodiversity of tobacco farmlands, and might make them more resistant to infection of pathogen.

Specifically, soil microbial community composition and structure changed significantly among four groups. And the abundance of Raltonia, which were conducive to tobacco bacterial wilt, was higher in control [44]. A previous study showed that green manure decrease tobacco disease rate by decreasing the amount of Raltonia and increasing the abundance of Bacillus using qPCR [45]. Basically, it was consistent with our result, that green manure could control pathogen populations. However, Pseudomonas and Bacillus had no significant negative correlation with tobacco disease rate, despite that they showed great potential in disease suppression [46]. For instance, Pseudomonas fuorescens could produce antifungal phloroglucinols in soils naturally suppressive to tobacco black root rot and reduced the extent of black root rot from $82 \%$ to $28 \%$ [47]. The reason could be that increasing the amount of probiotic bacteria was not the only way to improve tobacco health. For example, organic fertilizer could alleviate allelopathic autotoxicity of continuous cropping tobacco [48]. 
And the abundance pattern of other microbial populations might indicate their relationship with tobacco health. For example, the abundance of Acidobacteria was negatively correlated with tobacco disease rate, suggesting their potential in disease control. Acidobacteria is an acidophilic chemoorganotrophic bacterium, and it was reported that many sequences involved in nitrogen fixation and carbon cycling were founded to be associated with Acidobacteria [49, 50]. Acidobacteria also had genes that encode polyketide synthase and nonribosomal peptide synthase enzymes, which well known for their roles in the synthesis of siderophores, as well as other natural products such as antibiotics, antifungals, and antinematodal agents [51]. In this way, Acidobacteria, especially Gp4 and Gp6, probably play important roles in tobacco disease control. By contrast, the abundance of Proteobacteria, mainly composed of Dokdonella and Rhodanobacter, was positively correlated with tobacco disease rate. Dokdonella and Rhodanobacter are aerobic, chemo-organotrophic genera of Xanthomonadales order, which contains many plant pathogen species [52, 53]. Also, Rhodanobacter had the capability of denitrification, and might compete nitrogen source with tobacco [54]. In a word, no plant beneficial properties (e.g., nitrogen fixation) were identified in them, and they were potential nutrient competitor and disease inducer.

Finally, green manure, soil properties and microbial communities shaped tobacco health together. It has been realized for a long time that soil properties and microorganisms interact with each other, and both of them influencing plant growth and health [37, 45, 48]. Our study explored the interactions under the impacts of different green manure, as all of them changed significantly with green manure type. And their different change pattern indicated their relationship. For example, Almost all microbial populations that positively correlated to tobacco disease rate (e.g., Dokdonella and Rhodanobacter) were negatively correlated with soil total organic N and $\mathrm{Ca}$ content; while microbial populations that negatively correlated to tobacco disease rate (e.g., Acidobacteria_Gp4, Acidobacteria_Gp6) were usually positively related with contents of soil organic $\mathrm{N}$ and $\mathrm{Ca}$. The result suggested that green manure increased soil nutrients, which might improve tobacco health directly or indirectly through increasing the amount of probiotic bacteria.

\section{Conclusions}

In summary, we found that: (i) green manure increased soil nutrition, including N, $\mathrm{C}$ and $\mathrm{Ca}$ content; (ii) green manure had significant impacts on diversity, composition and structure of soil microbial communities; (iii) green manure decreased tobacco disease rate, which was mediated by soil properties and certain microbial populations. Acknowledgement: This work was supported by the National Natural Science Foundation of China (No. 31570113 and No. 41573072). Thanks to prof. Huaqun Yin and $\mathrm{Wu}$ Chen who helped design this study andcontributed material essential for the study, to Yabing Gu, Chao Zhang, Siyuan She, and Hongqi Yang for their help finish this experiment, and to Jiaojiao Niu and Jiemeng Tao for data analysis.

Author Contributions: Conceived and designed the experiments: Huaqun Yin and Wu Chen; performed the experiments: Yabing Gu and Hongwu Yang; Analyzed the data: Hongwu Yang, Jiaojiao Niu and Jiemeng Tao; contributed to sample collection: Chao Zhang and Siyuan She; Wrote the paper: Hongwu Yang; Revised the paper: Hongqi Yang.

Conflict of interest: The authors declare that they have no conflicts of interest. 


\section{Reference}

1. Matson, P.A., R. Naylor, and I. Ortiz-Monasterio, Integration of environmental, agronomic, and economic aspects of fertilizer management. Science, 1998. 280(5360): p. 112-115.

2. Hall, S.J., P.A. Matson, and P.M. Roth, NOx emissions from soil: implications for air quality modeling in agricultural regions. Annual Review of Energy and the Environment, 1996. 21(1): p. 311-346.

3. Cassman, K.G., Ecological intensification of cereal production systems: yield potential, soil quality, and precision agriculture. Proceedings of the National Academy of Sciences, 1999. 96(11): p. 5952-5959.

4. Cherr, C., J. Scholberg, and R. McSorley, Green manure approaches to crop production. Agronomy Journal, 2006. 98(2): p. 302-319.

5. Aulakh, M.S., T.S. Khera, and J.W. Doran, Yields and nitrogen dynamics in a rice-wheat system using green manure and inorganic fertilizer. 2000.

6. Bulluck, L., et al., Organic and synthetic fertility amendments influence soil microbial, physical and chemical properties on organic and conventional farms. Applied Soil Ecology, 2002. 19(2): p. 147-160.

7. Liebhardt, W., et al., Crop production during conversion from conventional to low-input methods. Agronomy Journal, 1989. 81(2): p. 150-159.

8. Gunapala, N. and K. Scow, Dynamics of soil microbial biomass and activity in conventional and organic farming systems. Soil Biology and Biochemistry, 1998. 30(6): p. 805-816.

9. Elfstrand, S., B. Båth, and A. Mårtensson, Influence of various forms of green manure amendment on soil microbial community composition, enzyme activity and nutrient levels in leek. Applied Soil Ecology, 2007. 36(1): p. 70-82.

10. Yadav, R., B. Dwivedi, and P. Pandey, Rice-wheat cropping system: assessment of sustainability under green manuring and chemical fertilizer inputs. Field Crops Research, 2000. 65(1): p. 15-30.

11. Elfstrand, S., K. Hedlund, and A. Mårtensson, Soil enzyme activities, microbial community composition and function after 47 years of continuous green manuring. Applied Soil Ecology, 2007. 35(3): p. 610-621.

12. Wyland, L., L. Jackson, and K. Schulbach, Soil-plant nitrogen dynamics following incorporation of a mature rye cover crop in a lettuce production system. The Journal of Agricultural Science, 1995. 124(01): p. 17-25.

13. Conklin, A.E., et al., Effects of red clover (Trifolium pratense) green manure and compost soil amendments on wild mustard (Brassica kaber) growth and incidence of disease. Plant and Soil, 2002. 238(2): p. 245-256.

14. Wiggins, B. and L. Kinkel, Green manures and crop sequences influence potato diseases and pathogen inhibitory activity of indigenous streptomycetes. Phytopathology, 2005. 95(2): p. 178-185.

15. Larkin, R.P. and T.S. Griffin, Control of soilborne potato diseases using Brassica green manures. Crop protection, 2007. 26(7): p. 1067-1077.

16. Bailey, K. and G. Lazarovits, Suppressing soil-borne diseases with residue management and organic amendments. Soil and Tillage Research, 2003. 72(2): p. 169-180.

17. da Rocha, U.N., L. van Overbeek, and J.D. van Elsas, Exploration of hitherto-uncultured bacteria from the rhizosphere. FEMS Microbiol Ecol, 2009. 69(3): p. 313-28.

18. Gardner, T., et al., Soil rhizosphere microbial communities and enzyme activities under organic farming in Alabama. Diversity, 2011. 3(3): p. 308-328.

19. Deng, J., et al., Shifts of tundra bacterial and archaeal communities along a permafrost thaw gradient in Alaska. Molecular Ecology, 2014: p. n/a-n/a.

20. Zhiyuan, W., J. Qingzhi, and H. Qinjian, Progress of Research on Tobacco Black Shank. Chinese Agricultural Science Bulletin, 2010. 21: p. 053.

21. Ramsey, M.H. and M. Thompson, High-accuracy analysis by inductively coupled plasma atomic emission spectrometry using the parameter-related internal standard method. Anal. At. Spectrom, 1987. 2: p. 497-502.

22. McKenzie, H.A. and H.S. Wallace, The Kjeldahl determination of Nitrogen: A critical study of digestion conditions-Temperature, Catalyst, and Oxidizing agent. Australian Journal of Chemistry, 1954. 7(1): p. 55-70.

23. Liu, C., et al., Rapid determination of organic carbon in marine sediment samples by potassium dichromate oxidation-ferrous sulphate titrimetry. Rock Miner Anal, 2007. 6(3): p. 205-208. 
24. Caporaso, J.G., et al., Ultra-high-throughput microbial community analysis on the Illumina HiSeq and MiSeq platforms. ISME J, 2012. 6(8): p. 1621-4.

25. Kong, Y., Btrim: A fast, lightweight adapter and quality trimming program for next-generation sequencing technologies. Genomics, 2011. 98(2): p. 152-153.

26. Magoč, T. and S.L. Salzberg, FLASH: fast length adjustment of short reads to improve genome assemblies. Bioinformatics, 2011. 27(21): p. 2957-2963.

27. Edgar, R.C., et al., UCHIME improves sensitivity and speed of chimera detection. Bioinformatics, 2011. 27(16): p. 2194-2200.

28. Edgar, R.C., Search and clustering orders of magnitude faster than BLAST. Bioinformatics, 2010. 26(19): p. 2460-2461.

29. Wang, Q., et al., Naive Bayesian classifier for rapid assignment of rRNA sequences into the new bacterial taxonomy. Appl Environ Microbiol, 2007. 73(16): p. 5261-7.

30. Statistical Package, R., $R:$ A language of environment for statistical computing. Vienna, Austria: R Foundation for Statistical Computing, 2009.

31. CLARKE, K.R., Non-parametric multivariate analyses of changes in community structure. Australian Journal of Ecology, 1993. 18: p. 117-143.

32. Calinski, PRINCIPLES AND PROCEDURES OF STATISTICS - A BIOMETRICAL APPROACH, 2ND EDITION - STEEL, RGD, TORRIE,JH. Biometrics, 1981. 37: p. 859-860.

33. E., S.P., L.J. C., and S.R. R., Multiple regression and correlation extensions of the Mantel test of matrix correspondence. Syst zool, 1986. 35(4): p. 627-632.

34. Tejada, M., et al., Effects of different green manures on soil biological properties and maize yield. Bioresour Technol, 2008. 99(6): p. 1758-1767.

35. Fauteux, F., et al., Silicon and plant disease resistance against pathogenic fungi. FEMS Microbiology letters, 2005. 249(1): p. 1-6.

36. Li, L., et al., Diversity enhances agricultural productivity via rhizosphere phosphorus facilitation on phosphorus-deficient soils. Proc Natl Acad Sci U S A, 2007. 104(27): p. 11192-6.

37. Fowler, C., L. Condron, and R. McLenaghen, Effects of green manures on nitrogen loss and availability in an organic cropping system. 2004.

38. Zhong, W., et al., The effects of mineral fertilizer and organic manure on soil microbial community and diversity. Plant and Soil, 2010. 326(1-2): p. 511-522.

39. Green, J.L., B.J. Bohannan, and R.J. Whitaker, Microbial biogeography: from taxonomy to traits. Science, 2008. 320(5879): p. 1039-43.

40. Marschner, P., E. Kandeler, and B. Marschner, Structure and function of the soil microbial community in a long-term fertilizer experiment. Soil Biology and Biochemistry, 2003. 35(3): p. 453-461.

41. Griffiths, B.S., et al., Ecosystem response of pasture soil communities to fumigation-induced microbial diversity reductions: an examination of the biodiversity-ecosystem function relationship. Oikos, 2000. 90(2): p. 279-294.

42. Tilman, D., et al., Diversity and productivity in a long-term grassland experiment. Science, 2001. 294(5543): p. 843-845.

43. Loreau, M., et al., Biodiversity and ecosystem functioning: current knowledge and future challenges. Science, 2001. 294(5543): p. 804-808.

44. YI You-jin, et al., Isolation and identification of endophytic Brevibacillus brevis and its biocontrol effect against tobacco bacterial wilt. Acta Phytopathologica Sinica, 2007. 37(3): p. 301-306.

45. Chen, Q., et al., Effects of bio-organic fertilizer application on population of Ralstonia solanacearum and Brevibacillus brevis in tobacco rhizosphere. Journal of Nanjing Agricultural University, 2012. 35(1): p. 75-79.

46. Ram, R.J., Community Proteomics of a Natural Microbial Biofilm. Science, 2005. 308: p. 1915.

47. Troxler, J., et al., Interactions between the biocontrol agent Pseudomonas fluorescens CHAO and Thielaviopsis basicola in tobacco roots observed by immunofluorescence microscopy. Plant Pathology, 1997. 46(1): p. 62-71.

48. Yang, H., et al., Effects of different fertilizers on functional diversities of microbial flora in rhizospheric soil of monoculture tobacco. ACTA AGRONOMICA SINICA, 2011. 37(1): p. $105-111$.

49. Sabree, Z.L., et al., Identification and characterization of the gene encoding the Acidobacterium capsulatum major sigma factor. Gene, 2006. 376(1): p. 144-51. 
50. Gough, H.L. and D.A. Stahl, Microbial community structures in anoxic freshwater lake sediment along a metal contamination gradient. ISME J, 2011. 5(3): p. 543-58.

51. Ward, N.L., et al., Three genomes from the phylum Acidobacteria provide insight into the lifestyles of these microorganisms in soils. Appl Environ Microbiol, 2009. 75(7): p. 2046-56.

52. Naushad, H.S. and R.S. Gupta, Phylogenomics and molecular signatures for species from the plant pathogen-containing order Xanthomonadales. PLoS One, 2013. 8(2): p. e55216.

53. Yoon, J.-H., S.-J. Kang, and T.-K. Oh, Dokdonella koreensis gen. nov., sp. nov., isolated from soil. International Journal of Systematic and Evolutionary Microbiology, 2006. 56(1): p. 145-150.

54. Kostka, J.E., et al., Genome sequences for six Rhodanobacter strains, isolated from soils and the terrestrial subsurface, with variable denitrification capabilities. J Bacteriol, 2012. 194(16): p. 4461-4462.

(C) 2016 by the authors; licensee Preprints, Basel, Switzerland. This article is an open access article distributed under the terms and conditions of the Creative Commons by Attribution (CC-BY) license (http://creativecommons.org/licenses/by/4.0/). 